\title{
The Product-Agnosia Effect: How More Visual Impressions Affect Product Distinctiveness in Comparative Choice
}

\author{
JAYSON SHI JIA \\ BABA SHIV \\ SANJAY RAO
}

\begin{abstract}
Consumer choice is often based on the relative visual appeal of competing products. Lay intuition, common marketing practice, and extant literature all suggest that more visual impressions help consumers distinguish products. This research shows that the opposite can occur. Rather than highlighting differences, seeing more pictures of products being compared can obfuscate perceptions, reduce distinctiveness and attractiveness of products, and increase choice uncertainty. Six experiments demonstrate that this "product-agnosia" effect is driven by shifts in the perceptual focus level of visual information processing. More visual impressions increased component-oriented and decreased gestalt-oriented perceptual focus, which undermined the distinctiveness of products distinguished on a gestalt level (e.g., by style). The effect reversed for products distinguished on a component level (e.g., by technical features). Overall, the efficacy of "showing more" depended on matching consumers' visual-processing style and the level (gestalt vs. component) at which products are differentiated.
\end{abstract}

A picture is said to be worth a thousand words. Behind the wisdom of this aphorism lies the recognition that everyday judgments and decisions are heavily dependent on visual information. It is thus no surprise that of the 11 million bits of information processed by the human brain per second, 10 million bits are dedicated to our visual system (Wilson 2002). The prominence of visually based decision making is especially relevant in consumer choice, where the relative visual appeal of various offerings often determines preferences and decisions. When browsing spring outfits in

Jayson Shi Jia (jjia@hku.hk) is assistant professor of marketing at Hong Kong University, Faculty of Business and Economics, K. K. Leung Building, the University of Hong Kong, Pok Fu Lam Road, Hong Kong. Baba Shiv (bshiv@stanford.edu) is Sanwa Bank, Limited, Professor of Marketing, and Sanjay Rao (rao_sanjay@gsb.stanford.edu) is a researcher, at the Graduate School of Business, Stanford University, 655 Knight Way, Stanford, CA 94305. The authors would like to thank the associate editor, three reviewers, Uzma Khan, Zakary Tormala, Jonathan Levav, Itamar Simonson, David Hardistry, and members of BabaLab at Stanford University for their feedback at various stages of this research.

Laura Peracchio served as editor and Rebecca Hamilton served as associate editor for this article.

Electronically published April 30, 2014 the glossy pages of Vogue, inspecting shoes from all possible angles on an interactive picture gallery at zappos.com, or going beyond pictures and closely examining different handbags on display at Bloomingdale's, consumers rely on visual information to compare, differentiate, and evaluate various products. The importance of visual appeal for consumers is recognized by marketers and retailers alike, who constantly bombard consumers with more visual impressions through phalanxes of posters, picture-laden websites, and strategically arranged product displays. Although the veritable visual feast that retail environments offer undeniably brings consumers a wealth of visual information, just how useful is this information? If a "picture" is worth a thousand words, does it imply that multiple pictures are worth many thousands of words?

Consumer choice fundamentally depends on the ability to distinguish between products during the decision-making process. In physical or online retail environments, this process is often heavily dependent on visual impressions. A common and instinctive strategy for marketers attempting to distinguish their products from others is to highlight differences with more visual impressions (often in the form of more pictures). For example, Internet retail shopping sites commonly have the option of displaying multiple pictures of products from different perspectives. Beyond intuition, 
extant literature also suggests that for visually based consumer decisions, more pictures should facilitate visual information processing and that "looking at more" is a natural inclination that aids decision making (Lurie and Mason 2007; Townsend and Sood 2011). On a basic level, increased visual processing of items in a consideration set fosters disambiguation and differentiation by providing more information about product features (Bloch, Brunel, and Arnold 2003; Carpenter, Glazer, and Nakamoto 1994). Contrary to such intuition, we propose that the common strategy of "looking at more" can backfire and that showing more visual impressions when comparing products can make the products seem less distinguishable, less unique, and less attractive. Since vision is fundamentally a constructive process (Biederman 1989; Treisman 1998), viewing more visual impressions can be counterproductive if doing so distorts how visual information is integrated, processed, and interpreted. In other words, looking at more can end up yielding less if it changes how we look in potentially detrimental ways.

Previous research suggests that deeper processing of information increases attention to details as one tries to differentiate objects through differences in minutia (Grill-Spector and Kanwisher 2005; Johnson 1984). Consistent with these findings, we suggest that showing consumers more pictures of products in a consideration set can lead to increased detailed, component-oriented and decreased holistic, gestalt-oriented perceptual focus in visual information processing (Lockhead, Gruenewald, and King 1978). Since many marketed products are distinguished by gestalt (rather than component level) aspects such as brand, style, and design (Aaker 1997; Bloch et al. 2003; Corfman 1991; Hagtvedt and Patrick 2008; Hekkert and Leder 2008; Patrick and Hagtvedt 2011; Thompson and Hamilton 2006), such a relative shift from gestalt- to component-level focus in visual information processing can be maladaptive and decrease perceptions of uniqueness and attractiveness. This change in perceptual focus is akin to comparing impressionist paintings by juxtaposing their brush strokes rather than their overall imagery or comparing shirts by contrasting their buttons instead of their overall pattern. However, one might expect the opposite effect to arise for products that are defined by component-level aspects such as details, technical features, and attributes. Overall, the relative benefit of viewing more visual impressions when comparing depends on the perceptual level at which consumers' visual processing occurs matching the perceptual focus level (gestalt vs. component) at which products are differentiated. When there is a mismatch of perceptual focus orientations, seeing more can ironically give rise to product agnosia, a visual homogenization that detracts from products' ultimate distinctiveness and appeal.

\section{CONCEPTUAL BACKGROUND}

The rationale behind the product-agnosia effect is that seeing more visual impressions during comparative evaluations shifts perceptual focus between two separate levels. The first is a higher level of overall evaluation that has alternatively been called gestalt, holistic, or global (Biederman 1989; Treisman 1998). The second is a lower level of detail-oriented evaluation that has alternatively been called component, detail, or local (Friedman 1979; Navon 1977). We propose that showing more pictures of comparison objects changes how one looks and changes one's level of visual evaluation from a gestalt to a component level, so that one starts focusing less on the overall and more on the details. Thus, comparing more visual impressions of products can potentially make products that are primarily differentiated by gestalt appeal seem more similar and less unique and subsequently increase choice uncertainty and decrease valuation of products. At the same time, the effect should be attenuated for products that are primarily differentiated on a component level.

\section{Shifting between Gestalt- to Component-Oriented Processing}

Research in perceptual psychology suggests that visual processing typically proceeds from an overall high-level recognition (gestalt level) to a progressively more detailed structural analysis (component level; Navon 1977). In the hierarchy of the visual world, this means that we first tend to perceive the forest before the trees, and trees before the leaves. The predominance of gestalt- over component-level processing corresponds with the greater importance of the gestalt whole over individual parts in visual recognition. Indeed, one cannot visually recognize objects without perceiving the whole, although one can still recognize objects without perceiving the parts (Biederman 1989; Treisman 1998). For example, one can visually form the impression that two faces are similar without having noticed the color of the eyes or shape of the nose, while the inverse is not true (Kimchi 1992).

Although gestalt-level processing is usually the default in visual processing, various factors, visual and cognitive, can foster a shift to component-level processing (Förster and Dannenberg 2010). Increased visual inspection is one such process. There are numerous reasons why deeper visual inspection and processing of additional visual impressions can interrupt visual processing at the gestalt level and result in a component-level perceptual focus (e.g., switching from looking at style, design, and patterns of a product to examining the individual touches, features, and nuts-and-bolts details). The visual-processing literature provides evidence that increased inspection moves visual focus forward in a "reverse hierarchical order" (Hochstein and Ahissar 2002), starting with a focus on the gestalt, where the overall gist of an object is first seen, processed, and captured in about 200 milliseconds (Friedman 1979; Oliva and Torralba 2006). However, once the gist has been captured, the acquisition of extra visual impressions progressively moves attention to details that are not seen at first glance and require increased visual scrutiny (Grill-Spector and Kanwisher 2005; Johnson 1984; Smith 2001). This suggests that when making product comparisons, the extra visual impressions from see- 
ing more pictures of each product should lead to attempts at identifying component-level differences across the products. Such a switch in relative focus to component-level differences is also a common consequence of numerous contrast-oriented visual and cognitive search strategies that come with deeper levels of information processing (Carpenter et al. 1994; Rensink 2002; Thompson and Hamilton 2006).

\section{The Impact of Shifting Perceptual Focus}

While shifts in perceptual focus often occur naturally and adaptively, there are also instances in which a situationally induced switch in perceptual focus can turn out to be maladaptive. Such changes can be detrimental when there is a mismatch between the perceptual focus of processing and the perceptual focus level that differentiates products. Shifts in perceptual focus of processing may arise via visual or cognitive routes. For example, looking at more pictures during product comparisons can move perceptual focus away from gestalt aspects. Similarly, adopting a component-oriented cognitive-processing style should also move perceptual focus from the gestalt to the component level.

For products that are differentiated on the gestalt level, such shifts in perceptual focus can give rise to product agnosia. Such products may provide similar functional utility and share common component-level features (e.g., lamps have shades, cars have wheels) but are often primarily differentiated by gestalt aspects such as product design (Bloch 1995; Hagtvedt and Patrick 2008). These gestalt aspects include dimensions such as shape, size, style, symmetry, balance, proportions, and contours-all of which can shape consumer evaluations and impression formation (Hekkert and Leder 2008; Veryzer 1999). For such products, a switch in perceptual focus essentially reduces focus on the aspects on which they are differentiated. Without visual differentiation on the perceptual level on which they are defined, products stand to lose their distinctiveness, desirability, and lasting appeal and become homogenous and forgettable.

However, not all products are visually differentiated on a gestalt level. Many products may be defined more by details, components, and technical features (Bloch et al. 2003; Carpenter et al. 1994). It should be noted that although many such products are technical products, their componentlevel differences must be visible; for example, screen quality of a television can be seen if the screen in turned on, whereas processing speed of a computer is difficult to convey in a two-dimensional picture. A perceptual focus mechanism predicts an attenuation of the product-agnosia effect for products distinguished relatively more by component-level visual differences.

Processing Style Changing Perceptual Focus. If relative perceptual focus on gestalt- versus component-level features drives product agnosia, then we would expect an exogenous manipulation of processing style (gestalt vs. component) to moderate the effect. Extant literature has shown that gestaltversus component-level perceptual processing (seeing a for- est or trees) is cognitively intertwined with gestalt- versus component-level conceptual processing (thinking broadly or narrowly about the forest or trees; for a review, see Förster and Dannenberg 2010). For example, being procedurally primed to see the gestalt can also result in greater higherlevel creative processing (Friedman et al. 2003) and broader, more inclusive social categorizations (Förster, Liberman, and Kuschel 2008). At the same time, being procedurally primed to think about the gestalt can also help in visually discerning higher-level visual patterns (Förster and Dannenberg 2010). In other words, the level at which one thinks about objects can change the level of one's visual processing and vice versa. The carryover effect of conceptual-processing style to visual-processing style occurs because both types of processing are based on common cognitive mechanisms (Förster et al. 2008). Thus, we expect that when comparing gestalt-oriented products, inducing gestalt processing should attenuate product agnosia, while inducing component-oriented processing should maintain product agnosia and its downstream effects. Conversely, the opposite should be the case for component-oriented products.

In the first four experiments that follow, which focus on products differentiated primarily by gestalt factors, we find that showing more pictures of products generates product agnosia - the loss of ability to distinguish between products (experiments 1 and 2). According to our conceptualization, product agnosia is driven by shifts in visual-processing style from gestalt- to component-level perceptual focus that renders products (that are defined by gestalt-level factors such as style and design) less distinctive and attractive. We test this proposition by moderating the product-agnosia effect directly via manipulation of visual-processing style (experiment 3 ) and indirectly via manipulation of stimulus- versus memory-based judgments (experiment 4). Finally, in the last two experiments, we show that the product-agnosia effect attenuates for products or comparison sets that are defined by component-level differences (experiments 5 and 6). Overall, this research highlights the importance of matching the visual information content of marketing with consumers' visual information-processing style; showing more visual impressions (e.g., more product images) only abets consumer choice and product evaluations when visual information content matches visual-processing style.

\section{EXPERIMENT 1: THE PRODUCT- AGNOSIA EFFECT}

The purpose of experiment 1 was to document the basic product-agnosia effect-that showing consumers more pictures of products under comparison can reduce the distinctiveness of products differentiated at the gestalt level. The basic experimental paradigm throughout this article was to show participants one picture or multiple pictures (one at a time) of each set of products, each on a separate page. The visual scenarios were designed to reflect the visual contexts in actual purchasing environments, particularly in online marketplaces where shoppers are shown more pictures of 
products from "additional views" to abet decision making. In addition, we explored the necessary conditions for the effect by testing (1) whether new visual information was required or if repeated inspection of the same visual information was sufficient and (2) whether the effect could occur for quicker visual inspections or if more careful and deliberate visual processing was required. The existence of the effect under different visual processing and information conditions would provide intuition on possible processes behind the hypothesized effect. For example, if product agnosia only occurs when new information is present, then familiarity is unlikely to be the underlying mechanism. Similarly, if sufficient visual-inspection time is necessary, then an information-processing mechanism is more likely than an exposure-driven process. Finally, we included a cognitive task at the end of the experiment to check whether an effect arose because showing more pictures taxed participants' cognitive resources.

\section{Method}

We used two actual products from the same product category (fashion sunglasses: DKNY vs. Michael Kors) as comparison objects in the interest of ecological validity and to control for unforeseen effects of cross-category comparisons. The product images and presentation formats were obtained from a leading online retailer (zappos.com). Participants recruited from Amazon's Mechanical Turk subject pool $(N=245)$ were randomly assigned to one of four visual conditions: single picture (single), multiple repeated picture (repeated), multiple unique picture with careful visual processing (multiple unique careful), and multiple unique picture with quick visual processing (multiple unique quick; fig. 1).

Visual Conditions. In the single-picture condition, participants were shown one picture of each pair of sunglasses (at the default isometric angle typically found in print and Internet product catalogs), each on a separate page. For hypothesis testing, the single-picture condition was always used as a baseline against which the effect of showing more pictures was contrasted.

In the multiple-repeated-picture condition, participants were shown the same image for each product seven times, each on a separate page. There was no time limit, and participants self-paced through each of the 14 pages. This allowed us to see the effect of seeing more pictures of a product when there was no new visual information in the pictures. Any differences between perception ratings between the single and multiple-repeated conditions will thus be the result of increased familiarity and exposure effects independent of new information.

In the multiple-unique-careful (multiple-careful) condition, participants were shown the "default" picture as well as six other unique pictures taken from different vantage points (see fig. 1) for each product. Each picture was on a new page, and participants self-paced through each new page/picture. This condition, which most accurately reflects how additional visual information is conveyed by retailers, allowed us to see the impact of additional pictures that carried new visual information when there was opportunity to carefully examine each picture.

The multiple-unique-quick (multiple-quick) condition contained the same pictures as the multiple-unique-careful condition. However, for each pair of sunglasses, all seven pictures were on one page, and participants only had 10 seconds to examine the pictures before the survey advanced automatically. Participants were warned to be prepared for the time limit before they could start viewing the pictures. This condition allowed us to see the impact of having additional visual information without the necessary time to carefully examine the each picture. For all conditions, the order of presentation of the products was randomized (some saw the DKNY sunglasses first; others saw the Michael Kors sunglasses first).

Dependent Variables. After the picture viewings, we measured choice, liking ratings, similarity perceptions, and choice uncertainty. The default picture (isometric view) of each pair of sunglasses (the first pictures of each pair of sunglasses in all conditions) was displayed on the top of each dependent measures page to aid comparative evaluation and to maintain ecological validity (since shoppers in both physical and online stores usually have the products in front of them during decision making). Participants were first asked to imagine that they were shopping at the store and choosing between the two sunglasses, with the option of deferring choice. If participants deferred choice, they were asked to make a forced choice on the next page so that the following dependent measures would still be meaningful. Participants next rated how regretful (1 [not regretful at all] to 7 [very regretful]) and confident they were in their choice ( 1 [not confident at all] to 7 [very confident]), how much they liked the sunglasses they picked (1 [not at all] to 7 [very much]), how similar the sunglasses were (1 [not similar at all] to 7 [very similar]), and how distinctive each pair of sunglasses was to each other (1 [not distinctive at all] to 7 [very distinctive]). The scale measures were averaged into an index for similarity $(\alpha=.75)$ and an index for choice uncertainty $(\alpha=.76)$.

Cognitive Resources. At the end of the experiment, participants were asked to solve three anagrams and two visual geometric manipulation puzzles. The number of correct answers was summed to create a cognitive resources score. Time spent was also measured by a page timer.

\section{Results}

Cognitive Resources. Planned contrasts showed no significant differences in cognitive resource scores $\left(M_{\text {single }}=\right.$ $3.11, \mathrm{SD}=1.14 ; M_{\text {repeat }}=3.25, \mathrm{SD}=1.29 ; M_{\text {careful }}=$ $3.05, \mathrm{SD}=1.10 ; M_{\text {quick }}=3.34, \mathrm{SD}=.96 ;$ all $F<1$ ) or time spent solving the puzzles $\left(M_{\text {single }}=170\right.$ seconds, SD $=92 ; M_{\text {repeat }}=172$ seconds, $\mathrm{SD}=120 ; M_{\text {careful }}=183$ seconds, $\mathrm{SD}=114 ; M_{\text {quick }}=196$ seconds, $\mathrm{SD}=117$; all 
FIGURE 1

STIMULI PRESENTED IN EXPERIMENT 1

\section{Single Picture Condition}

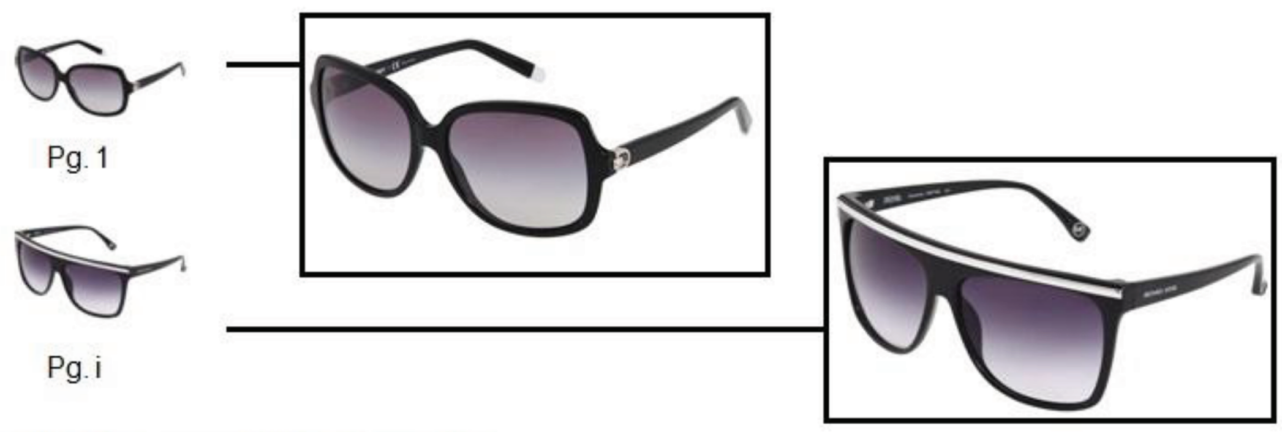

Multiple Repeated Picture Condition

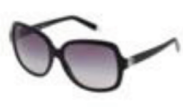

Pg. 1

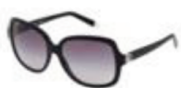

Pg. 2

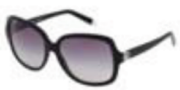

Pg. 3

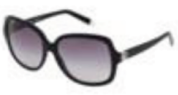

Pg. 4

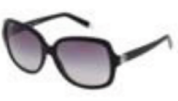

Pg. 5

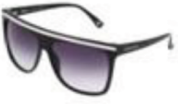

Pg. V
Pg. 6
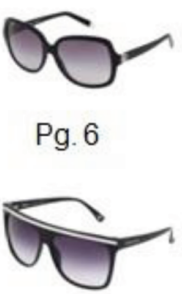

Pg. vi

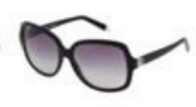

Pg. 7

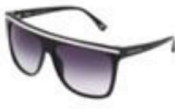

Pg.i

Pg. ii

Pg. iii

$\mathrm{Pg}$. iv

Multiple Unique Picture Conditions - Careful and Quick

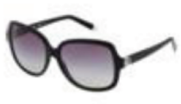

Pg. 1

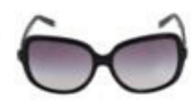

( Pg. 2

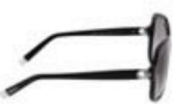

Pg. 3

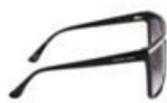

Pg. iii

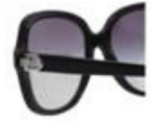

Pg. 4

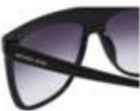

Pg.iv

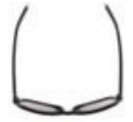

Pg. 5

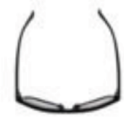

Pg. v

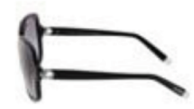

Pg. 6

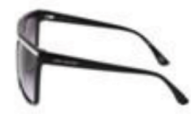

Pg. vi

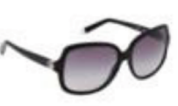

Pg. 7

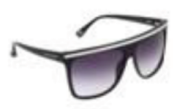

Pg.vii )
$F<1$ ) between any of the visual conditions. There was no difference even after removal of outliers for the timing measure (all $F<1$ ). Indeed, we did not expect any cognitive resource depletion effects since participants only viewed a small number of images for two products.

Time Spent on Picture Pages. Page timers showed that participants spent a mean duration of 8.12 seconds $(\mathrm{SD}=$ 4.58) on each of the two picture pages in the single-picture condition (16.2 seconds total), 2.73 seconds $(\mathrm{SD}=1.50)$ on each of the 14 picture pages in the multiple-repeated condition (38.2 seconds total), 5.55 seconds $(\mathrm{SD}=5.51)$ on each of the 14 picture pages in the multiple-careful condition (77.8 seconds total), and 10 seconds (by automatic page timer) for each of the two picture pages (which contained seven pictures each) in the multiple-quick condition ( 20 seconds total, average of 1.43 seconds per picture). Thus, it would appear that participants quickly "clicked through" the identical images in the repeated condition but inspected pictures more carefully in the careful condition (all $p<.01)$.

Product Agnosia. We found evidence of the productagnosia effect occurring only in the multiple-careful condition but not in the multiple-repeated or quick conditions. 
Compared against the single-picture condition, participants in the multiple-careful condition had more choice deferral $\left(M_{\text {single }}=26 \%, M_{\text {careful }}=49 \% ; \chi^{2}(120)=6.72, p=.01\right.$; fig. $2 A$ ) and higher perceptions of similarity of the products $\left(M_{\text {single }}=3.12, M_{\text {careful }}=3.58 ; t(117)=2.12, p<.05\right.$; fig. $2 B$ ). Although not significant, there was a pattern of greater choice uncertainty $\left(M_{\text {single }}=2.28, M_{\text {careful }}=2.75 ; t(117)=\right.$ $1.89, p=.06)$ and less liking $\left(M_{\text {single }}=5.15, M_{\text {careful }}=\right.$ $4.62 ; t(117)=1.73, p=.08)$. As expected, there was no difference in choice share between the two sunglasses $(p=$ $.64)$ - in other words, product agnosia did not drive choice share from one option to another (e.g., from a weaker brand to a stronger brand). Rather, product agnosia seemed to make both options less distinctive and less attractive.

There were no significant differences in choice deferral $\left(M_{\text {single }}=26 \%, M_{\text {repeat }}=35 \%, M_{\text {quick }}=31 \%\right)$, choice uncertainty $\left(M_{\text {single }}=2.28, M_{\text {repeat }}=2.38, M_{\text {quick }}=2.12\right)$, liking $\left(M_{\text {single }}=5.15, M_{\text {repeat }}=4.85, M_{\text {quick }}=5.26\right)$, and similarity perception $\left(M_{\text {single }}=3.12, M_{\text {repeat }}=3.29, M_{\text {quick }}\right.$ $=3.23$ ) between the single and repeated and multiple-quick conditions (all $p>.2$ ).

\section{Discussion}

Experiment 1 provides an initial demonstration of the product-agnosia effect. Although intuition would have suggested that showing more pictures of products should highlight their differences and abet differentiation, we found the opposite effect. Participants who viewed more visual impressions for each product (as operationalized by looking through more pictures, one at a time) perceived the comparison products as more similar and less attractive than did participants who received fewer visual impressions and saw each product only once. The results on choice deferral and uncertainty were consistent with a notion that product agnosia made the two products seem more similar and harder to distinguish. That product agnosia and greater choice uncertainty was complemented by trending lower attractiveness ratings is consistent with prior research showing that

\section{FIGURE 2A}

CHOICE DEFERRAL UNDER DIFFERENT VISUAL CONDITIONS (EXPERIMENT 1)

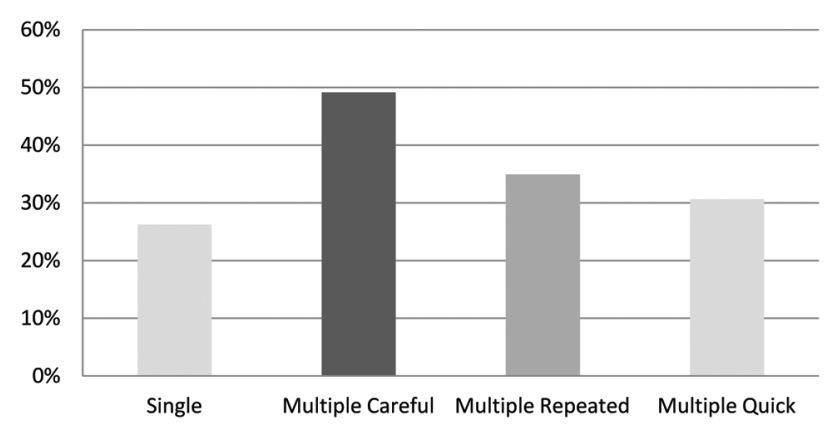

FIGURE 2B

\section{SIMILARITY PERCEPTIONS UNDER DIFFERENT VISUAL CONDITIONS (EXPERIMENT 1)}

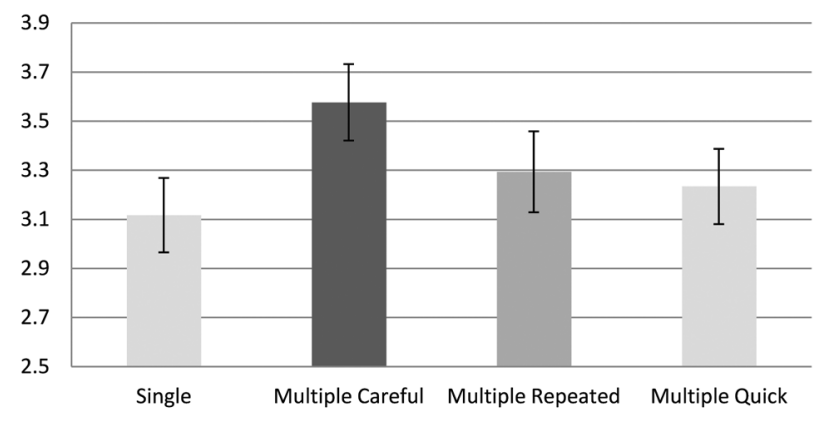

harder choices can result in less consumer satisfaction and commitment toward products (Mogilner, Shiv, and Iyengar 2013). Indeed our measures showed significant internal and conceptual consistency; liking was negatively correlated with similarity ratings $(r=-.25, p<.01)$, deferral $(r=$ $-.66, p<.01)$, and choice uncertainty $(r=-.47, p<.01)$, while similarity ratings were correspondingly positively correlated with deferral $(r=.22, p<.01)$ and choice uncertainty $(r=.20, p<.01)$.

Experiment 1 also provided process insight by identifying two necessary conditions, (1) new visual information and (2) sufficient time for processing. First, product agnosia did not arise simply from seeing more pictures (in the multiplerepeated condition). We only observed the effect from increased inspection of new visual information. This suggests that product agnosia is not simply driven by an increase in object familiarity, which underlies mere exposure, satiation, or visual habituation related mechanisms. However, this result is consistent with prior research showing that the repetition of different visual configurations can disrupt visual recognition by changing the relative basis of visual analyses (Lockhead et al. 1978). Second, merely having new visual information did not induce product agnosia when there was limited time for visual inspection (10 seconds) in the multiple-quick condition. This suggests that beyond being exposed to additional visual information, participants in the multiple-careful condition also inspected the images with greater scrutiny than would have been possible in the multiple-quick condition. This boundary condition is consistent with visual perception research suggesting that at-a-glance inspection yields only the "gist," while detail-oriented processing only comes about with sufficient time and scrutiny (Smith 2001).

Experiment 1 also provides evidence against a cognitive overload account - that seeing more pictures induced overload that reduced participants' ability to discern products. We found no between-condition differences in participants' cognitive resource scores at the end of the experiment. Furthermore, an overload account would also have predicted 
that viewing 12 more pictures in the multiple-repeated and quick conditions should have been sufficient to induce product agnosia, which was not the case. Overall, the results of experiment 1 were in line with our hypothesized productagnosia account: that increased attention given to different details of new visual information changes perceptual focus, which then affects comparative evaluations. This account is investigated in the next experiment, where a thought-listing task qualifies changes in attention and focus when decision makers are shown more visual impressions.

\section{EXPERIMENT 2: THOUGHT LISTING}

Experiment 2 extended the product-agnosia effect to another product category (duffel bags: Dakine vs. Victorinox), expanded our set of dependent measures, and explored the product-agnosia mechanism with a thought-listing task. In particular, the thought-listing task investigated whether seeing more pictures could have altered how individuals were processing more visual impressions. This allowed us to test our hypothesis that seeing more pictures could have led to a shift in perceptual focus from the gestalt to the component level, which then reduced products' distinctiveness and attractiveness.

\section{Method}

One hundred and two participants recruited from an online participant database maintained by the Stanford University Graduate School of Business Behavioral Lab were randomly assigned to the single-picture (one picture of each bag) or the multiple-picture condition (seven unique pictures of each bag, each on a different page). The visual stimuli were presented using the same basic experimental paradigm as experiment 1 (single and multiple-careful conditions).

In contrast to experiment 1 , and in order to triangulate measures of product agnosia, we measured perceptions of distinctiveness with a relative uniqueness measure. Participants rated how unique each bag looked relative to another (1 [not unique at all] to 7 [very unique]), indicated choice of bag (for incentive compatibility, participants had the chance to win their chosen bag in a lottery), predicted liking for the chosen bag ( 1 [not like at all] to 7 [like very much]), rated interest in learning more about the bags (1 [not interested at all] to 7 [very interested]), and reported interest in shopping for the two bags (1 [not interested at all] to 7 [very interested]). The order of questions was reversed relative to experiment 1 , in order to rule out question-order effects. Relative uniqueness scores for each bag were averaged to create a composite score for perceived uniqueness $(r=.45, p<.01)$. Since attitudinal strength of interest is conceptually related to strength of preference, the two interest measures and the predicted liking measure were averaged to create a strength of preferences index $(\alpha=.73)$.

At the end of the survey, participants were asked to list their thoughts about the products. Two independent coders coded responses for total number of thoughts listed and number of component-level thoughts. In line with prior re- search on perceptual focus (Kimchi 1992), coders categorized descriptions of functions and features as "component oriented" and overarching descriptions of style and dimensions as "gestalt oriented." For example, "professional looking," "light," and "sporty" were coded as gestalt oriented, while "extra side pockets," "prominent logo," and "toughlooking fabric" were coded as component oriented. Due to the high interrater reliability achieved $(r=.97$ for total thoughts, and $r=.99$ for perceptual focus), these scores were averaged to form an index score for total thoughts and an index score for perceptual focus.

\section{Results and Discussion}

Consistent with experiment 1 , we found that perceptions of product uniqueness, which is conceptually related to product distinctiveness and opposite to product similarity, were lower in the multiple-picture than in the single-picture condition $\left(M_{\text {single }}=3.67, M_{\text {mult }}=3.16 ; t(97)=2.07, p<.05\right)$. Similarly, strength of preference for the products was lower in the multiple-picture condition than in the single-picture condition $\left(M_{\text {single }}=4.31, M_{\text {mult }}=4.95 ; t(97)=2.34, p<\right.$ $.05)$. Across conditions, strength of preferences was significantly correlated with uniqueness ratings $(r=.54, p<.01)$. As expected, there were once again no significant differences between conditions in choice of bag $(p>.1)$, which implies that the bags were not differentially affected by viewing more visual impressions. Most germane to our interests, the thought-listing task showed a higher number and proportion of component-level thoughts (all $p<.05)$ in the multiplepicture condition $(M=2.09, \operatorname{Pr}($ component $)=0.55)$ than in the single-picture condition $(M=1.46, \operatorname{Pr}$ (component) $=0.39$ ) but showed no difference in the total number of thoughts between the two conditions $\left(M_{\text {single }}=3.09, M_{\text {mult }}\right.$ $=3.36, p=.39$ ).

Experiment 2 complements experiment 1 in showing that inspecting more pictures of comparison objects primarily differentiated by gestalt factors can render them less unique, less preferred, and less interesting. These measures are all strong predictors of consumer interest and purchase intentions and suggest that the product-agnosia effect can be detrimental for product positioning and brand image (Aaker 1997). The thought-listing task also yielded evidence that inspecting more visual impressions can lead to a shift from gestalt- to component-level visual processing. In experiment 3 , we explicitly test this account by directly manipulating style of perceptual focus.

\section{EXPERIMENT 3: MANIPULATING THE STYLE OF VISUAL PROCESSING}

The thought-listing results of experiment 2 suggest that the product-agnosia effect is driven at least in part by a shift in style or level of perceptual focus. In experiment 3, we assessed the mechanism by directly manipulating perceptual focus and exogenously inducing gestalt- versus componentoriented visual processing. If the negative effect of product agnosia is caused by a switch in perceptual focus (from the 
gestalt to the component level), then inducing gestalt-oriented processing should attenuate the effect. Correspondingly, if consumers are trapped in a component-level perceptual focus during product agnosia, then exogenously inducing component-oriented processing should only maintain product agnosia.

\section{Method}

One hundred and thirty-eight participants from the same national online pool as experiment 2 were informed that they were participating in two purportedly unrelated studies. Part 1 was presented as an "image-processing study," and part 2 was presented as a separate "product evaluation study."

Manipulating Visual-Processing Style. In part 1, we induced gestalt- versus component-level visual-processing style using a procedure adopted from Friedman et al. (2003). Participants were randomly assigned to the gestalt- or component-level processing condition, in both of which they were sequentially shown seven maps of different American states (Arkansas, Iowa, Massachusetts, Pennsylvania, South Carolina, Tennessee, and Wisconsin), each on a different page. In the gestalt-processing condition, participants were asked to look at the overall features of each state map. In the component-level processing condition, participants were asked to focus their attention on a marker that pointed to a city near the center of the map (Little Rock, Waterloo, Worcester, Selinsgrove, Columbia, McMinnville, and Wausau). For comparison purposes, we also included a control condition that skipped the processing-style manipulation of part 1 and was contained only in part 2.

Manipulation Check for Perceptual Focus. After viewing the maps, participants completed a Navon perceptualfocus manipulation check (Navon 1977). First, participants were asked to prepare to report their initial reactions to the image on the next page. On the next page, participants were presented with a large letter $\mathrm{E}$ that was formed by smaller letter A's. Participants were then asked whether they first saw "a big E" or "a lot of small A's," whether the letter E or A was more obvious on first glance, and how easy it was to discern the letter $\mathrm{E}(1=$ not easy at all, $7=$ very easy $)$. Participants in a gestalt-processing mind-set should find it easier to react to the large $\mathrm{E}$ than the smaller A's (Navon 1977).

Visual Manipulation. In part 2, we used the same basic experimental procedure as in experiment 1. Participants were asked to imagine that they were shopping for boat shoes (Polo vs. Sperry) and were randomly assigned to a single- or multiple-picture condition. In the single-picture condition, they were shown a single picture of each boat shoe, and in the multiple-picture condition, they were shown seven different pictures of each boat shoe, each on a new page.

Participants were then asked to rate how unique each shoe was (1 [not at all unique] to 7 [very unique]), which shoe they would have picked (this choice was incentivized: participants had the chance to win their chosen shoes in a lottery), and how much they think they would like the shoe they picked (1 [not at all] to 7 [very much]). The two uniqueness scales (one for each shoe) were combined into one uniqueness index $(r=.79)$.

\section{Results}

Manipulation Check. Manipulation check results showed that we successfully induced differences in visual-processing style and perceptual scope. More participants reported seeing the big E rather than the small A's first $(F(1,101)$ $=12.8, p<.01)$, that the letter $\mathrm{E}$ was more obvious than A on first glance $(F(1,100)=13.1, p<.01)$, and that $\mathrm{E}$ was easier to spot $(F(1,101)=7.97, p<.01)$ in the gestaltoriented condition than in the component-oriented condition.

Next, we tested our hypothesized perceptual focus account: that induced gestalt perceptual focus should counteract product agnosia, while increased component perceptual focus should maintain product agnosia. Thus, there should be differences between the gestalt and control conditions but not between the component and control conditions. We submitted ratings of uniqueness, predicted liking, and choice to a 3 (control, gestalt-level processing, component-level processing) $\times 2$ (single/multiple pictures) ANOVA. Consistent with our predictions, we found statistically significant interactions between our perceptual focus manipulation and visual condition for uniqueness $(F(2,130)$ $=4.89, p<.01$; fig. $3 A)$ and liking ratings $(F(2,130)=$ $5.14, p<.01$; fig. $3 B$ ). In particular, as described in the post hoc tests below, we found evidence of product agnosia reversing in the gestalt-processing condition but persisting in the component-processing condition as compared against the control condition. We also replicated the basic product-agnosia main effect, as evidenced by lower ratings of uniqueness ( 2.43 vs. 3.75$)$ and liking (4.00 vs. 5.25$)$ when participants viewed more pictures in the control condition (all $p$

\section{FIGURE 3A}

PERCEPTIONS OF COMPARISON OBJECTS' UNIQUENESS UNDER INDUCED GESTALT- VERSUS COMPONENT-LEVEL PERCEPTUAL FOCUS (EXPERIMENT 3)

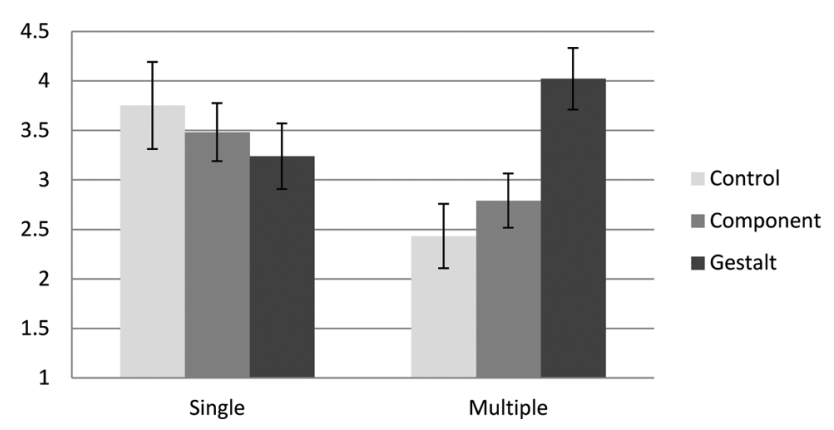


FIGURE 3B

\section{PREDICTED LIKING OF COMPARISON OBJECTS UNDER INDUCED GESTALT- VERSUS COMPONENT-LEVEL PERCEPTUAL FOCUS (EXPERIMENT 3)}

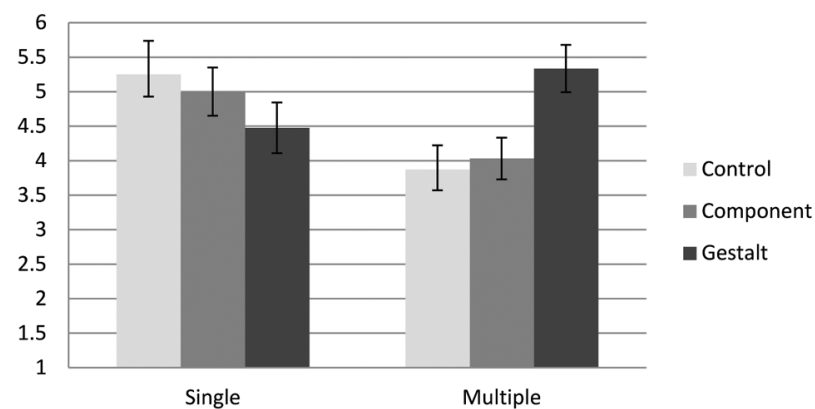

$<$.05). Consistent with previous experiments, we found no interaction or main effects for choice $(F(2,130)<1, p=$ $.58)$.

Gestalt versus Control. Post hoc tests revealed that seeing multiple versus single pictures had a reverse effect in the gestalt as compared to the control condition. When participants were shown multiple pictures, gestalt processing resulted in higher ratings of uniqueness $\left(M_{\text {control }}=2.43\right.$, $\left.M_{\text {gestalt }}=4.02, p<.01\right)$ and liking $\left(M_{\text {control }}=3.87, M_{\text {gestalt }}\right.$ $=5.33, p<.01)$ as compared against the control condition. There were no differences in uniqueness $\left(M_{\text {control }}=3.75\right.$, $\left.M_{\text {gestalt }}=3.24, p=.20\right)$ and liking $\left(M_{\text {control }}=5.25, M_{\text {gestalt }}\right.$ $=4.48, p=.70$ ) ratings between gestalt and control conditions in the single-picture condition, where there was no scope for product agnosia to occur in the first place. One might note that within the gestalt-processing condition, the uniqueness and liking ratings are trending higher in the multiple-picture condition than the single-picture condition (all $p=.09$ )—an "enhancement" effect that we did not predict. One possible reason for this unexpected trending difference is that participants had more occasions to inspect gestaltlevel features in the multiple-picture condition. Greater elaboration on the defining and distinguishing gestalt-level features of the product may then have then resulted in higher product ratings.

Component versus Control. Post hoc tests revealed that there were no significant differences in uniqueness and liking ratings between the control and component-processing conditions in either the multiple-picture (uniqueness: $M_{\text {control }}$ $=2.43, M_{\text {comp }}=2.79, p=.695$; liking: $M_{\text {control }}=4.00$, $M_{\text {comp }}=4.03, p=.95$ ) or single-picture conditions (uniqueness: $M_{\text {control }}=3.75, M_{\text {comp }}=3.54, p=.69$; liking: $M_{\text {control }}$ $=5.25, M_{\text {comp }}=4.96, p=.62$ ). In other words, consistent with our predictions, we find that the basic product-agnosia effect persists under component-level processing, where visual condition (number of pictures) again has a main effect on perceptions of uniqueness. However, our initial concep- tualization did not predict a trending within-condition main effect of number of pictures for component processing (uniqueness: $p=.07$; liking: $p=.04$ ). It is possible that induced local processing does not hinder uniqueness perceptions when viewing one picture, but when viewing multiple pictures, participants had more occasions to engage in detrimental component-oriented processing, which lowered product ratings even more.

Gestalt versus Component. Finally, as a corollary of the above findings and consistent with our hypotheses, post hoc tests showed higher ratings of uniqueness and liking in the multiple-picture condition under gestalt- as compared to component-level processing (all $p<.01$ ). As with previous contrasts, there was no difference in the single-picture condition (all $p>.3$ ). Overall, the gestalt versus component comparisons were analogous to the gestalt versus control comparisons.

\section{Discussion}

The persistence of the product-agnosia effect after induced component processing and its reversal after induced gestalt processing suggests that the product-agnosia effect is driven by changes in perceptual-processing style. Indeed, the parallel results between the component-processing condition and the control condition suggest that the style of processing is the same in both (i.e., both have componentlevel perceptual focus). Together, the results of experiments 1-3 suggest that viewing more pictures of comparison objects led to relatively more component- and less gestalt-level focus. When participants' visual-processing style was component level and focused on details, viewing more visual impressions reduced perceptions of distinctiveness and predicted liking. However, when one takes a metaphorical step back under gestalt-level processing, viewing more visual impressions begins to yield benefits for a product's perceived distinctiveness and predicted liking. Experiment 3 highlights that viewing more pictures of comparison objects does not unequivocally result in product agnosia, which reconciles our findings with lay intuition and previous literature on the benefits of more visual information. Rather, it is how we process given visual information that determines whether seeing more visual impressions is beneficial for product evaluations.

\section{EXPERIMENT 4: STIMULUS- VERSUS MEMORY-BASED JUDGMENTS}

In experiment 4, we further explored the perceptual focus mechanism with an indirect manipulation and an additional theory test: by contrasting memory- versus stimulus-based judgments. Specifically, we examined the occurrence of product agnosia when product judgments were made in immediate response to the visual stimuli or through recall from memory. In our previous experiments, we displayed the default picture of products above the dependent measures, so judgments were based on immediately present stimuli (just 
as in a store or catalog, participants could look at the objects while evaluating them). Previous research suggests that for stimuli judgments, the focus can be at the gestalt or the component level or both (Grill-Spector and Kanwisher 2005). However, information of stimuli recalled from memory tends to be predominantly gestalt oriented (Bartlett 1932) because memory and recollections are generally more in the form of a gist rather than details (Hochstein and Ahissar 2002; Nedungadi 1990). Consequently, the manipulation of stimulus- versus memory-based judgments serves as an additional theory test for perceptual focus: if product agnosia is driven by shifts in perceptual focus level, then the effect should attenuate when judgments are based on recall.

\section{Method}

Visual Conditions. We repeated the same basic experimental procedure as the previous three studies with the same product category as experiment 1 (sunglasses: DKNY vs. Michael Kors). One hundred and sixteen participants recruited from a national online pool were first randomly assigned to the single-picture (one picture of each pair of sunglasses) or multiple-picture condition (seven unique pictures of each pair of sunglasses).

Manipulating Recall. After viewing the products, participants were randomly assigned to either the stimulus or the recall condition. In the stimulus condition, a picture of each pair of sunglasses was displayed above the dependent measures. This allowed participants to make evaluations of the sunglasses while still looking at them (as in the previous three experiments). In the recall condition, participants were first given a 2-minute reading comprehension filler task before proceeding to the dependent measures page. On this page, there were no pictures of the sunglasses. Participants were given the same initial instructions as previous experiments and were not warned that they may be asked to rely on memory for evaluations.

Dependent Variables. Participants then rated how unique each pair of sunglasses was (1 [not unique at all] to 7 [very unique]), how similar the sunglasses were (1 [not similar at all] to 7 [very similar]), how comparable the sunglasses were (1 [not comparable at all] to 7 [very comparable]), how easy it was to distinguish between the sunglasses (1 [not easy at all] to 7 [very easy]), and how much they were willing to pay for each pair of sunglasses (on a sliding scale [ $\$ 0$ $\$ 100]$ ). The uniqueness scores were averaged to create a composite score of overall perceived uniqueness $(r=.54$, $p<.01)$, and the three similarity measures were averaged to create a composite score of similarity $(\alpha=.71$; the last measure was reverse coded).

\section{Results}

If memory-based judgments are more gestalt oriented in perceptual scope than stimulus-based judgments, we would expect a similar pattern of interactions as in experiment 3 .
In particular, memory-based processing, like gestalt processing, should counteract the overly component-oriented perceptual focus induced by more visual impressions. However, no such reversal should occur for stimulus-based judgments. We obtained results consistent with these expectations after submitting measurements of uniqueness, similarity, and willingness to pay to a 2 (stimulus or recall) $\times 2$ (single or multiple images) ANOVA. We found significant interactions for perceptions of uniqueness $(F(1,105)=8.63, p$ $<.01$; fig. $4 A)$, similarity $(F(1,107)=8.33, p<.01$; fig. $4 B)$, and willingness to pay $(F(1,87)=3.84, p=.05$; fig. $4 C$ ). In other words, we found that retrospective evaluations reversed the product-agnosia effect.

Simple Main Effects. Within-condition differences of estimated marginal means in the stimulus condition were consistent with the results of experiments $1-3$. Seeing more pictures had a marginally significant negative effect on product evaluations, with lower ratings of uniqueness $\left(M_{\text {single }}=\right.$ $\left.4.05, M_{\text {mult }}=3.36 ; F(1,101)=3.44, p=.07\right)$ and higher perceptions of similarity $\left(M_{\text {single }}=4.03, M_{\text {mult }}=4.45 ; F(1\right.$, $103)=3.25, p=.07)$. Although this result was not statistically significant, the pattern was consistent with the statistically significant results of previous studies. When participants engaged in recall processing, the product-agnosia effect was reversed, and viewing more pictures improved product evaluations with relatively higher ratings of uniqueness $\left(M_{\text {single }}=3.37, M_{\text {mult }}=4.25 ; F(1,101)=5.26, p<\right.$ $.05)$ and decreased perceptions of similarity $\left(M_{\text {single }}=4.66\right.$, $\left.M_{\text {mult }}=4.09 ; F(1,103)=5.17, p<.05\right)$. Similarly, for stimulus judgments, willingness to pay was marginally lower in the multiple-picture condition $\left(M_{\text {single }}=\$ 40.78\right.$, $\left.M_{\text {mult }}=\$ 30.00 ; F(1,87)=2.79, p<.1\right)$, while under recall judgments, willingness to pay was not negatively influenced and in fact trended in the opposite direction $\left(M_{\text {single }}=\right.$ $\left.\$ 30.33, M_{\text {mult }}=\$ 38.16 ; F(1,87)=1.27, p=.26\right)$. Again, while we cannot conclusively state that viewing more pictures increased willingness to pay under recall processing, this result at the very least suggests that retrospective eval-

\section{FIGURE 4A}

PERCEPTIONS OF COMPARISON OBJECTS' UNIQUENESS UNDER STIMULUS- VERSUS RECALL-BASED EVALUATION (EXPERIMENT 4)

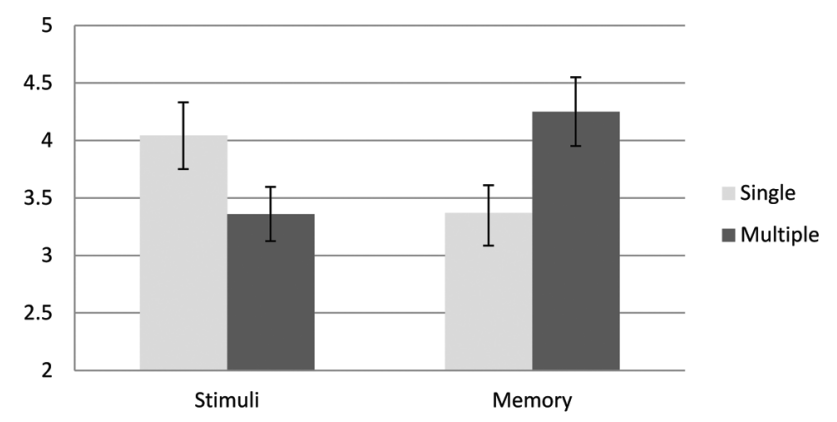


FIGURE 4B

PERCEPTIONS OF COMPARISON OBJECTS' SIMILARITY UNDER STIMULUS- VERSUS RECALL-BASED EVALUATIONS (EXPERIMENT 4)

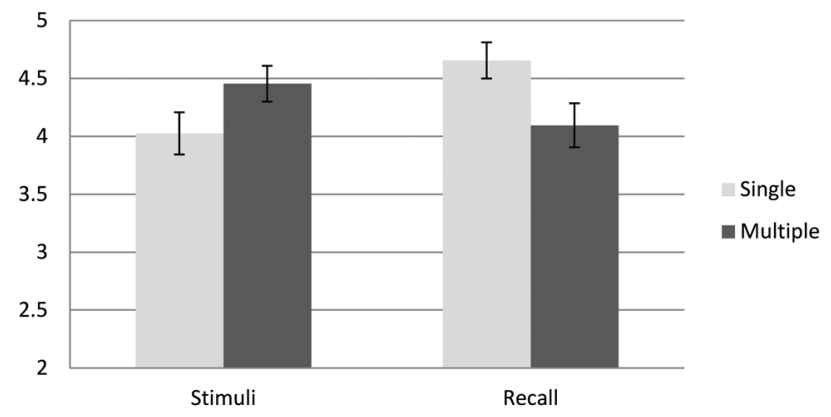

uations can negate product agnosia's negative effect on product valuation.

\section{Discussion}

The implications of experiment 4 are twofold. First, it provides an additional theory test that product agnosia is driven by a shift in perceptual focus since memory cues are generally more gestalt than component oriented (Bartlett 1932). Second, this experiment has direct managerial implications since it reverses the damage of product agnosia with an ecologically relevant moderator. In many decisionmaking contexts, the consumer has the option to postpone decisions. Indeed, our experimental conditions were designed to be analogous to the following Internet shopping scenarios: (1) examining visual information on a retail website until a purchase decision is made (stimulus-based judgments) or (2) leaving a retail website after saving your product choice in a "shopping basket" and considering the purchase later (memory-based judgments). The results of experiment 4 show that while more visual impressions can hurt evaluations in the former situation, they may actually help in the latter. In experiments 5 and 6, we explore additional boundaries of the product-agnosia effect. In particular, we test products that are differentiated at the component rather than the gestalt level, for which our process findings suggest that product agnosia should not manifest.

\section{EXPERIMENT 5: PRODUCTS DISTINGUISHED BY COMPONENT AND NOT GESTALT}

An implicit necessary condition for the product-agnosia effect is for comparison products to be distinct on the gestalt but similar on the component level. Our previous experiments showed that product agnosia occurred because inspecting additional visual impressions resulted in a shift of perceptual focus from the gestalt-level distinctions that dif- ferentiated products to the component-level details that homogenized products. The products in our previous experiments, like many in the real world, were relatively more distinguished by gestalt-level visual features such as overall style and design (Aaker 1997; Bloch et al. 2003; Corfman 1991; Hekkert and Leder 2008). However, this is not always the case; products fall on a continuum in the comparative importance of gestalt versus component (Bloch 1995), and some are distinguished more by component-level features (Townsend and Sood 2011). For example, technical products like touch screen mobile phones have relatively similar overall designs (flat rectangular screen) and are distinguished more by specific visible features (e.g., button location, camera placement, operating system). Experiment 5 tests whether the product-agnosia effect is attenuated when products in a comparison set are similar on the gestalt level but distinctive on the component level. For such products, the detriment of decreased focus on gestalt-level features from more visual impressions might be offset by the benefit of greater focus on the relatively more important component-level features.

\section{Method}

Using the same experimental procedure as previous studies, we randomly assigned 135 participants from Amazon's Mechanical Turk online subject pool to view one or multiple unique pictures of a component-oriented product: touch screen smart phones (HTC EVO vs. LG Marquee phones). In an independent pretest $(N=134)$ we confirmed that touch screen mobile phones were considered to be relatively more component oriented $(p<.01)$, whereas products in previous experiments were considered to be relatively more gestalt oriented (all $p<.01$ ).

Dependent Variables. Participants rated how much they liked each phone (1 [not at all] to 7 [very much]), how unique the phones were (1 [not unique at all] to 7 [very unique]), how similar (1 [not similar at all] to 7 [very similar]) and how distinctive (1 [not distinctive at all] to 7 [very

FIGURE 4C

\section{WILLINGNESS TO PAY FOR COMPARISON OBJECTS UNDER STIMULUS- VERSUS RECALL-BASED EVALUATIONS} (EXPERIMENT 4)

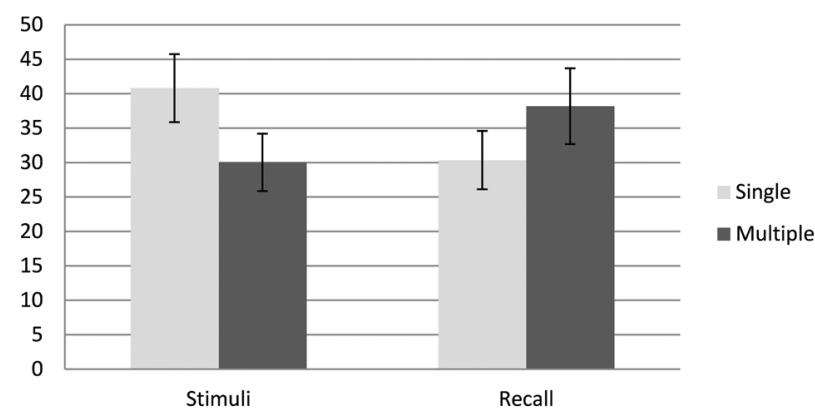


distinctive]) each phone was from the others, and how much they were willing to pay for each phone, before being asked to imagine choosing between the phones in a shopping context. Participants were also given the opportunity to defer their choice ("choose neither-go to the next store to see more models"). Participants then rated their predicted liking of their chosen phone (1 [not at all] to 7 [very much]) and how regretful (1 [not regretful at all] to 7 [very regretful]) and how confident ( 1 [not confident at all] to 7 [very confident]) they were in their choice. The scale measures were also averaged into an index for liking $(\alpha=.62)$, an index for similarity $(\alpha=.61)$, and an index for choice uncertainty $(\alpha=.78)$.

\section{Results}

In line with the perceptual focus account, we did not find evidence of product agnosia occurring for the componentoriented mobile phones. There were no significant differences in liking $\left(M_{\text {single }}=5.35, M_{\text {mult }}=5.59 ; t(132)=1.62\right.$, $p=.11)$ and similarity ratings $\left(M_{\text {single }}=4.06, M_{\text {mult }}=\right.$ 4.10, $p=.86$ ) between the multiple- and single-picture conditions. In fact, product ratings trended to be more positive in the multiple-picture condition: willingness to pay was marginally greater $\left(M_{\text {single }}=\$ 96, M_{\text {mult }}=\$ 108 ; t(132)\right.$ $=1.77, p=.08)$ and uniqueness perceptions were higher $\left(M_{\text {single }}=3.72, M_{\text {mult }}=4.20 ; t(131)=2.30, p<.05\right)$ in the multiple-picture condition. Furthermore, there was a marginally significant decrease in choice deferral $\left(\chi^{2}(1,135)\right.$ $=3.39, p=.07)$ and greater choice confidence $\left(M_{\text {single }}=\right.$ $\left.2.24, M_{\text {mult }}=2.81 ; t(132)=2.63, p<.01\right)$ in the multiplepicture condition.

\section{Discussion}

An attenuation (and partial reversal) of the product-agnosia effect for component-oriented products establishes an important boundary condition in support of a perceptual focus account. In particular, the relative benefit or harm of looking at more pictures when comparing products depends on the perceptual focus orientation of the products being examined. This result also reconciles our results with previous research showing the benefits of familiarity, mere exposure, and increased information processing on product evaluations (Bloch et al. 2003; Carpenter et al. 1994; Zajonc 1968). One might note that the differences in product measures were not all statistically significant. This might have occurred because gestalt perceptions still mattered to a degree for the comparison products, and thus the shift in perceptual focus had an ambivalent effect.

That the product-agnosia effect occurs for gestalt-oriented products but does not occur for component-oriented products is not easily explained by alternative accounts unrelated to perceptual focus. For example, one could have wondered whether the symmetrical visual orientations of the pictures of product pairs (e.g., for every picture of product A, there was always a corresponding picture of product $\mathrm{B}$ from the same angle) were inducing the increased similarity percep- tions that characterized product agnosia. However, the reversal of the effect with the same experimental paradigm shows that the visual procedure alone does not determine whether product agnosia occurs. Rather, product agnosia requires (1) a shift in perceptual focus (experiment 3 ) and (2) for that shift in perceptual focus to be mismatched in its relation to the perceptual focus level that differentiates products.

\section{EXPERIMENT 6: MANIPULATING COMPONENT- VERSUS GESTALT-LEVEL DIFFERENCES}

Experiment 5 showed that product agnosia reverses for a product that is primarily distinguished by component-level differences. Experiment 6 further explored this key boundary condition by exogenously manipulating whether a comparison set for one product category (dresses) is differentiated on gestalt or component levels. In particular, we manipulated whether one dress is compared against a dress that is different on the gestalt level (style of dress) but similar on the component level (cut of dress) or a dress that is similar on the gestalt level but different on the component level. On the basis of the results of previous experiments, we would expect product agnosia to only occur when two dresses are distinguished by gestalt features (style) but for the opposite effect to occur when two dresses are distinguished by component features (cut). The within-productcategory design of experiment 6 also provides a stronger test of the perceptual focus account. Since all previous experiments included only one set of binary contrasts within the same product category, it was still possible that product agnosia was driven by some contextual particularities such as product type. However, directly inducing and reversing product agnosia for the same product category provides even stronger evidence for a perceptual-focus mechanism.

\section{Method}

Manipulating Visual Inspection and Perceptual Focus Orientation of Contrast. We repeated the same basic experimental procedure as previous studies with images of two women's dresses, which differed from each other on either a gestalt (style) or a component level (cut). One hundred and thirty participants (all female) recruited from Amazon's Mechanical Turk online subject pool were randomly assigned to view (1) single pictures or (2) seven unique pictures of two dresses that were either (1) similar in gestalt and different in component or (2) different in gestalt and similar in component. The product comparisons comprised a black-and-white-striped style dress with a long cut that was paired with either (1) a black-and-white-striped style dress with a short cut (similar gestalt, different component) or (2) a fuchsia floral print style dress with a long cut (different gestalt, similar component). An independent manipulation check confirmed that the dresses' style of pattern (e.g., black-and-white stripes or fuchsia floral print) was 
considered to be relatively more gestalt than component oriented as compared to cut $(t(269)=8.44, p<.01)$.

Dependent Variables. As with previous studies, we measured similarity perceptions, liking ratings, and choice uncertainty. Participants first rated how much they liked each dress (1 [not at all] to 7 [very much]), how much they liked the pattern of each dress (1 [not at all] to 7 [very much]), how similar the dresses were (1 [not similar at all] to 7 [very similar]), and how distinctive the dresses were from each other (1 [not distinct at all] to 7 [very distinct]). On the next page, which had pictures of the dresses at the top, participants were asked to imagine that they were shopping at the store and making a choice between the two dresses. Participants were also given the chance to defer their choice ("choose neither-go to the next store to see more dresses"). Participants then rated how regretful (1 [not regretful at all] to 7 [very regretful]) and confident they were in their choice (1 [not confident at all] to 7 [very confident]). The scale measures were averaged into an index for liking $(\alpha=.88)$, an index for similarity $(\alpha=.77)$, and an index for choice uncertainty $(\alpha=.78)$.

\section{Results}

A switch in perceptual focus is only detrimental when it results in less focus on what differentiates products and greater focus on what homogenizes products. Thus, product agnosia should only arise when products are primarily differentiated by gestalt features (style of pattern), while the reverse effect should arise when products are primarily differentiated by component features (cut). A 2 (single vs. multiple pictures) $\times 2$ (similar style different cut vs. different style similar cut) ANOVA yielded results in line with these predictions for choice deferral $(F(1,122)=5.63, p<.05$; fig. $5 A)$, similarity perceptions $(F(1,122)=4.32, p<.05$; fig. $5 B)$, liking ratings $(F(1,122)=5.02, p<.05$; fig. $5 C)$, and choice uncertainty $(F(1,122)=4.60, p<.05$; fig. $5 D)$, There was no significant interaction on choice of dress $(p$

FIGURE 5A

CHOICE DEFERRAL FOR PRODUCTS THAT DIFFER ON THE GESTALT OR COMPONENT LEVEL (EXPERIMENT 6)

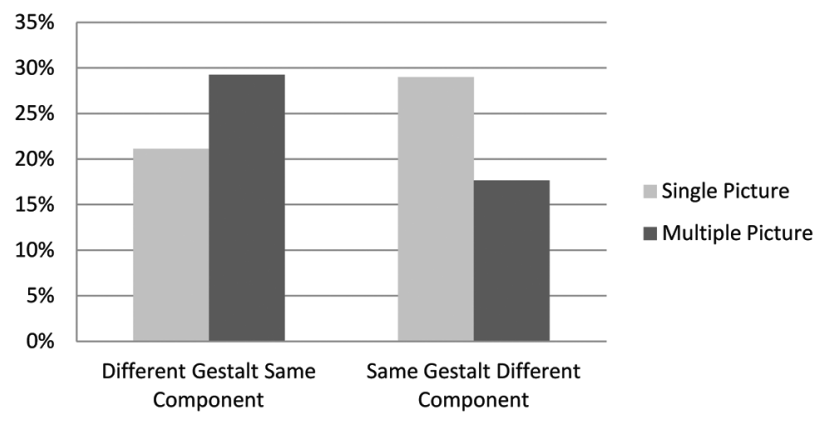

FIGURE 5B

SIMILARITY RATINGS FOR PRODUCTS THAT DIFFER ON THE GESTALT OR COMPONENT LEVEL (EXPERIMENT 6)

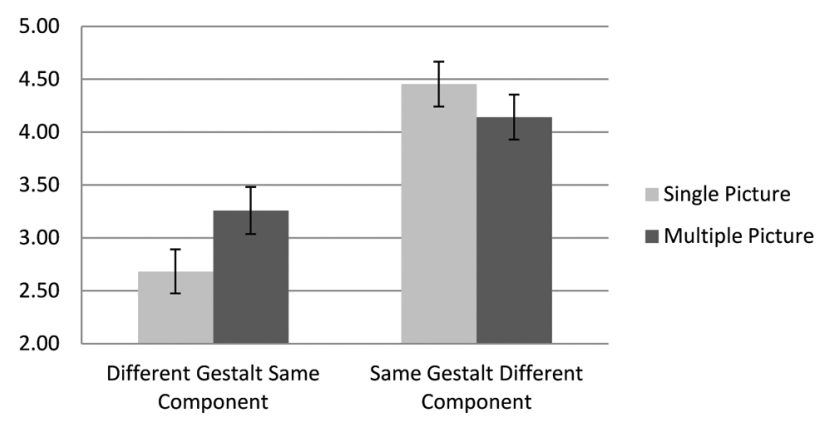

$=.63$ ); more pictures did not result in one dress gaining choice share over the other.

\section{Discussion}

Experiment 6 replicates product agnosia in a new comparison paradigm, provides further evidence of a perceptual focus mechanism, and highlights that the impact of product agnosia depends on the perceptual focus level that products are differentiated by. The results also reconcile the negative impact of product agnosia in experiments $1-4$ with the effect's attenuation for component-oriented product categories in experiment 5 within a single perceptual focus framework. Rather than being a strictly detrimental effect, product agnosia seems to have an ambivalent impact on consumers' perceptions; more visual impressions only impair product evaluations when comparison objects are differentiated on the gestalt level but boost product evaluations when comparison objects are differentiated on the component level. Thus, the product-agnosia phenomenon is a kind of (mis)matching effect in which more visual impressions are beneficial if processing style and perceptual focus orientation of products are consistent but detrimental if they are inconsistent.

\section{GENERAL DISCUSSION}

Despite the intuition that showing more visual impressions should help distinguish products, this research showed that the opposite can occur. In a variety of product categories, showing additional visual impressions can ironically undermine products' distinctiveness, decrease attractiveness, increase choice deferral and uncertainty, and lower monetary valuations. This product-agnosia effect arises when viewing more visual impressions of comparison objects leads to more component-oriented processing and less gestalt-oriented processing. Such a shift in perceptual focus is detrimental for the comparative evaluation of products primarily distinguished by gestalt-level differences like style and design 
FIGURE 5C

LIKING RATINGS FOR PRODUCTS THAT DIFFER ON THE GESTALT OR COMPONENT LEVEL (EXPERIMENT 6)

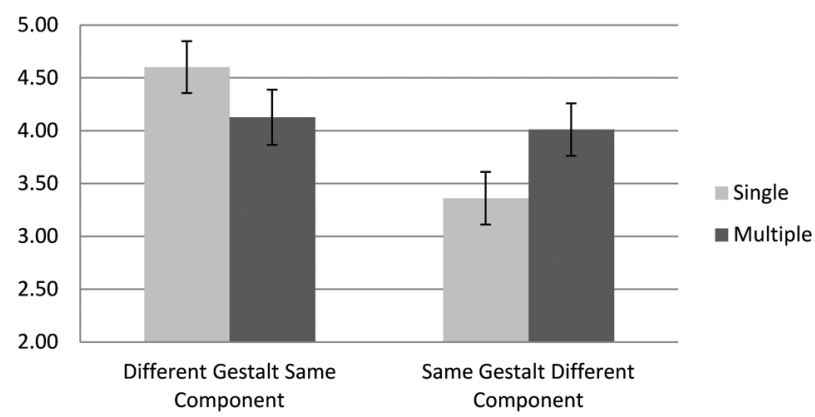

(experiments 1 and 2). In line with this mechanism, the effect is moderated by style of visual processing (experiment 3 ) and stimulus- versus memory-based judgments (experiment 4). However, the effect reverses for products that are distinguished by component- rather than gestalt-level differences (experiments 5 and 6). Thus, more pictures are detrimental only when they cause a mismatch in how consumers process visual information.

This research takes a first step in answering the question posed at the start of the article: If a picture is worth a thousand words, then are multiple pictures worth even more? The answer is that it depends on how you look at the pictures. Our finding that seeing only one picture of each product yielded more positive evaluations does not make any normative claims about the intrinsic value of information; clearly, 14 different pictures objectively carry more information than two pictures. Rather, we argue that seeing more pictures can impair comparative evaluations because they change how one looks at objects. Showing more pictures only hurts comparative product evaluations if visual-processing style is inconsistent with products' perceptual focus orientation. Thus, the impact of showing consumers more visual impressions depends on successfully matching the orientation or format of visual content and the visual-processing style of consumers.

\section{Directions for Future Research}

Depth of Decision Making. Our demonstration of the product-agnosia effect and its attendant processes is consistent with a growing body of research highlighting the benefits of relying on initial, simple, and quick impressions. For example, research on "thin slices" suggests that overall judgments are heavily based on first impressions, which can be formed within seconds of initial exposure (Ambady, Bernieri, and Richeson 2000). In a variety of contexts including interpersonal attraction to teacher evaluations, thin slices were found to be as accurate as more extensive and careful observations. Recent research in decision making has also shown that overthinking and overcomplicating choice can lead to increased focus on relatively unimportant aspects, which results in people becoming mired in a "decision quicksand" (Schrift, Netzer, and Kivetz 2011; Sela and Berger 2012). Indeed, our phenomenon can be thought of as a kind of "visual quicksand" and is largely driven by a too narrow focus. This is underlined by the fact that the productagnosia effect reverses if people take a metaphorical step back and employ gestalt processing (experiment 3) or use visual memory cues in lieu of immediate visual stimuli (experiment 4). The existence of cognitive and metacognitive parallels in decision-making literature to our visually based phenomenon suggests that there is scope for future research to unify the kindred undercurrents of our research streams: that quick impressions can help if gestalt-level processing is important but that increased effort and focus (whether cognitive or visual) can hurt if component-level aspects are relatively unimportant.

Information Overload. On a superficial level, our experimental paradigm may appear similar to information overload experimental paradigms, for example, choice overload, resource depletion, and feature fatigue effects (Iyengar and Lepper 2000; Scheibehenne, Greifeneder, and Todd 2010; Thompson, Hamilton, and Rust 2005), since participants were asked to visually process more information in one condition. However, several of our experimental results run against such mechanisms. An overload account would have predicted that viewing repeated pictures of the same product in experiment 1 was more cognitively taxing than viewing just one picture, which was not the case. Manipulation checks also showed no differences in participants' cognitive resource scores at the end of experiment 1 between any of the visual conditions. Finally, that attenuations and reversals of the product-agnosia effect arose in experiments 3-6 also runs against an overload mechanism. It is likely that no information overload effects arose simply because our "see more pictures" manipulation was not particularly cognitively taxing. Participants viewed at most 12 additional

\section{FIGURE 5D}

CHOICE UNCERTAINTY FOR PRODUCTS THAT DIFFER ON THE GESTALT OR COMPONENT LEVEL (EXPERIMENT 6)

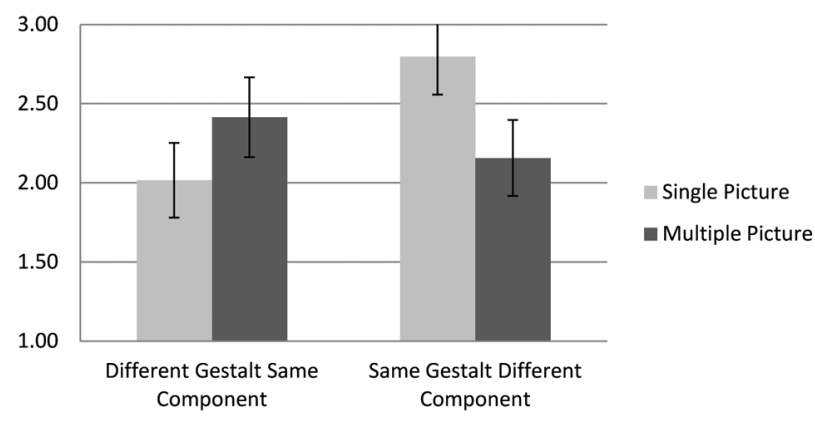


images of everyday products: a task that is relatively trivial for the vast parallel-processing capabilities of the human visual system. However, the notion of having created maladaptive difficulties in visual or cognitive processing without actually having undermined our cognitive resources, an idea that is seen more frequently in visual-processing literature (Biederman 1989; Treisman 1998), is certainly a motif that future investigators could expand on in the consumer behavior domain.

Comparative versus Noncomparative Multiple Exposure Paradigms. The product-agnosia experimental paradigm uniquely combines comparative evaluations and multiple visual exposures. This is in contrast to extant consumer choice paradigms, which use only one or the other. For example, repeat exposure effects like the mere-exposure effect (Zajonc 1968) examine the effect of multiple visual exposures on a single object. In our experiments, two products are always shown the same number of times (one or seven) within each condition, and thus the comparative judgments actually benefit from the same amount of exposure, familiarity, and fluency. Furthermore, the product-agnosia effect only occurs when new visual information is present (experiment 1) and will not occur if participants are reexposed to the same picture repeatedly (which is analogous to the mere-exposure paradigm). The comparative nature of the product-agnosia paradigm similarly separates itself from satiation, visual habituation, cognitive overload, or mental wear-out paradigms, none of which are comparative and which several of our manipulation checks further rule out.

Single versus Multiple Images. In a similar vein, the product-agnosia experimental design yields different results from comparative paradigms that do not use multiple visual exposures. For example, research by Förster and colleagues (Förster 2009; Förster and Dannenberg 2010) found that more global processing should generally increase perceptions of similarity between objects relative to local processing. On first glance, this finding may seem contrary to product agnosia, which shows that more gestalt (global) and less component (local) perceptual focus can decrease perceptions of similarity between objects. However, this discrepancy likely arises because Förster (2009) employed isolated single images or memory-based evaluations of visual stimuli, while product agnosia depended on multiple visual impressions under stimuli processing. Indeed, we obtained results consistent with Förster (2009) within our single-picture and memory-based conditions. Future research may investigate additional crossroads between product agnosia and similar but contrasting experimental paradigms in greater depth.

Degree and Category of Difference. In this research, the products used as visual stimuli were relatively similar and comparable and belonged to the same product categories. While intracategory product comparisons are common in consumer judgment, cross-category comparisons or comparisons between drastically different products may be interesting extensions of the product-agnosia paradigm. For example, previous literature on assimilation and contrast effects suggests that while assimilation is more likely to occur when objects are very similar, contrast is more likely to occur when objects are very different (Mussweiler 2001). This would predict that viewing more pictures of product pairings that are highly distinct should increase distinctiveness ratings. At the same time, a separate research stream has demonstrated that less comparable objects, such as objects in different categories, may automatically be abstracted to a more gestalt (and comparable) level and not compared on a component level (Johnson 1984), which makes assimilation effects more likely (Förster et al. 2008), a set of findings in line with our results. Likely, the persistence of product agnosia in cross-category comparisons will depend heavily on how categorization and grouping occurs, which experiment 6 suggests can be highly contextualized and susceptible to framing effects.

Orientation of Stimuli. In an unreported study, we tested whether the effect could be driven by similarities in how the products were positioned in all visual conditions, which then induced component-style processing. We reran the single-picture and multiple-unique-picture conditions of experiment 1 along with a condition in which the orientation and perspective of products was different. In this condition, we used the same pictures as the multiple-unique condition but rotated alternating pictures of each product 180 degrees so that the perspective of the first picture of the first product was flipped relative to the first picture of the second product, and so on. We measured similarity, distinctiveness, and uniqueness, which were combined into a similarity index $(\alpha=.76)$. We replicated the basic effect that products in the multiple-unique condition were perceived to be more similar than in the single-picture condition $\left(M_{\text {single }}=2.88\right.$, $\left.M_{\text {mult uniq }}=3.50 ; t(106)=2.68, p<.05\right)$. Product agnosia also persisted in the different perspectives condition $\left(M_{\text {single }}\right.$ $\left.=2.88, M_{\text {mult uniq rot }}=3.37 ; t(105)=2.15, p<.05\right)$. In fact, there was no significant difference between the rotated and nonrotated multiple-unique-picture conditions $(p=$ .59 ), which suggests that perspective and orientation was not an independent effect.

Precise Visual Mechanism. Despite showing that product agnosia is driven by a change in perceptual focus, the precise visual mechanism behind this change remains an open question. For example, we do not know what details participants initially focused on, what their path of visual inspection was, or when perceptual focus switches. Future investigations may use eye-tracking or implicit measures of visual attention and gaze to explore the precise changes in visual scrutiny that may underlie the effect. Although we exclusively used a single-multiple visual impression paradigm to explore product agnosia, there is conceptually no reason why product agnosia cannot also be induced with single pictures; if participants were forced to examine one picture for a sufficient duration, perhaps their gaze would start shifting toward the details. Alternatively, seeing how participants manipulate or scrutinize a 3-D digital object or 
physical products would also be an ecologically relevant alternative operationalization of the effect.

\section{Conclusion}

This research shows that the intuition of "showing more is better" is often not true and that the marketer's instinct to highlight differences by offering more visual impressions can backfire. When product agnosia occurs, looking at more can lead to seeing less if shifts in perceptual focus make consumers lose track of what differentiated products in the first place. Rather, the relative benefit of showing more visual impressions depends on whether the relative perceptual focus orientation of the products meshes with consumers' visual-processing style. Beyond taking the first step in demonstrating the product-agnosia effect, we hope that the findings will encourage greater exploration of the counterintuitive influences of visual information and visual processing on consumer choice.

\section{DATA COLLECTION INFORMATION}

The first author analyzed the data from experiment 1 , which were collected from Amazon's Mechanical Turk online subject pool with support from the Stanford University Graduate School of Business Behavioral Lab. The first and second authors analyzed the data from experiment 2 , which were collected from a nationally representative online subject pool managed by the Stanford University Graduate School of Business Behavioral Lab. The first author analyzed the data from experiment 3 , which were collected from the same online subject pool as experiment 2 . The first and second authors analyzed the data from experiment 4 , which were from the same online subject pool as experiment 2 . The first author analyzed the data from experiments 5 and 6, which were collected from Amazon's Mechanical Turk with support from the Stanford University Graduate School of Business Behavioral Lab.

\section{APPENDIX \\ FIGURE A1}

PRODUCTS USED IN EXPERIMENTS 1 AND 4

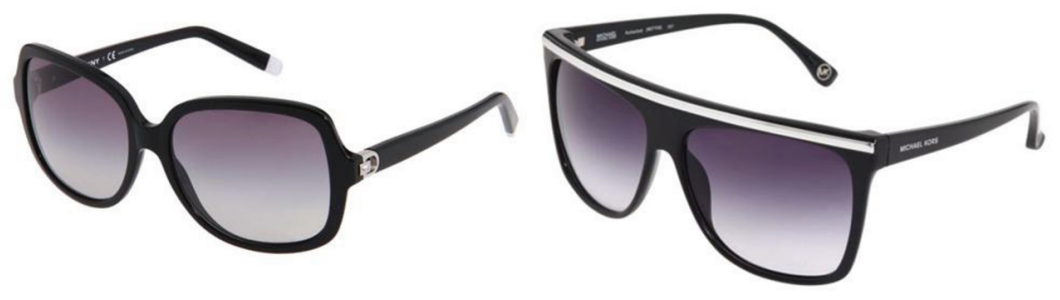

Note._DKNY (left) and Michael Kors (right) sunglasses.

FIGURE A2

PRODUCTS USED IN EXPERIMENT 2
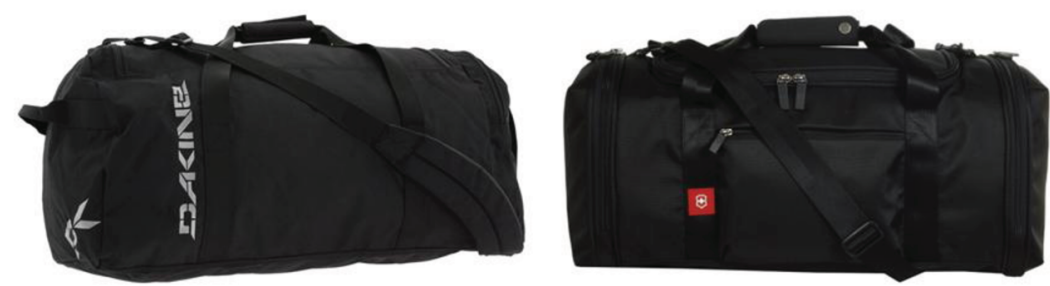

NOTE.-Dakine (left) and Victorinox (right) duffel bags. 
FIGURE A3

PRODUCTS USED IN EXPERIMENT 3
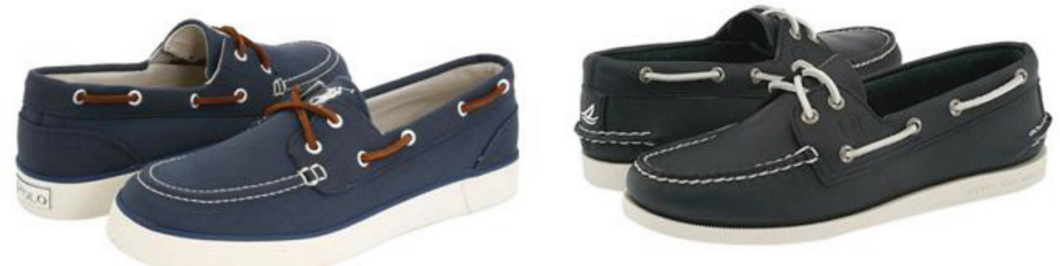

NotE.-Ralph Lauren Polo (left) and Sperry Topsider (right) boat shoes.

\section{FIGURE A4}

PRODUCTS USED IN EXPERIMENT 5
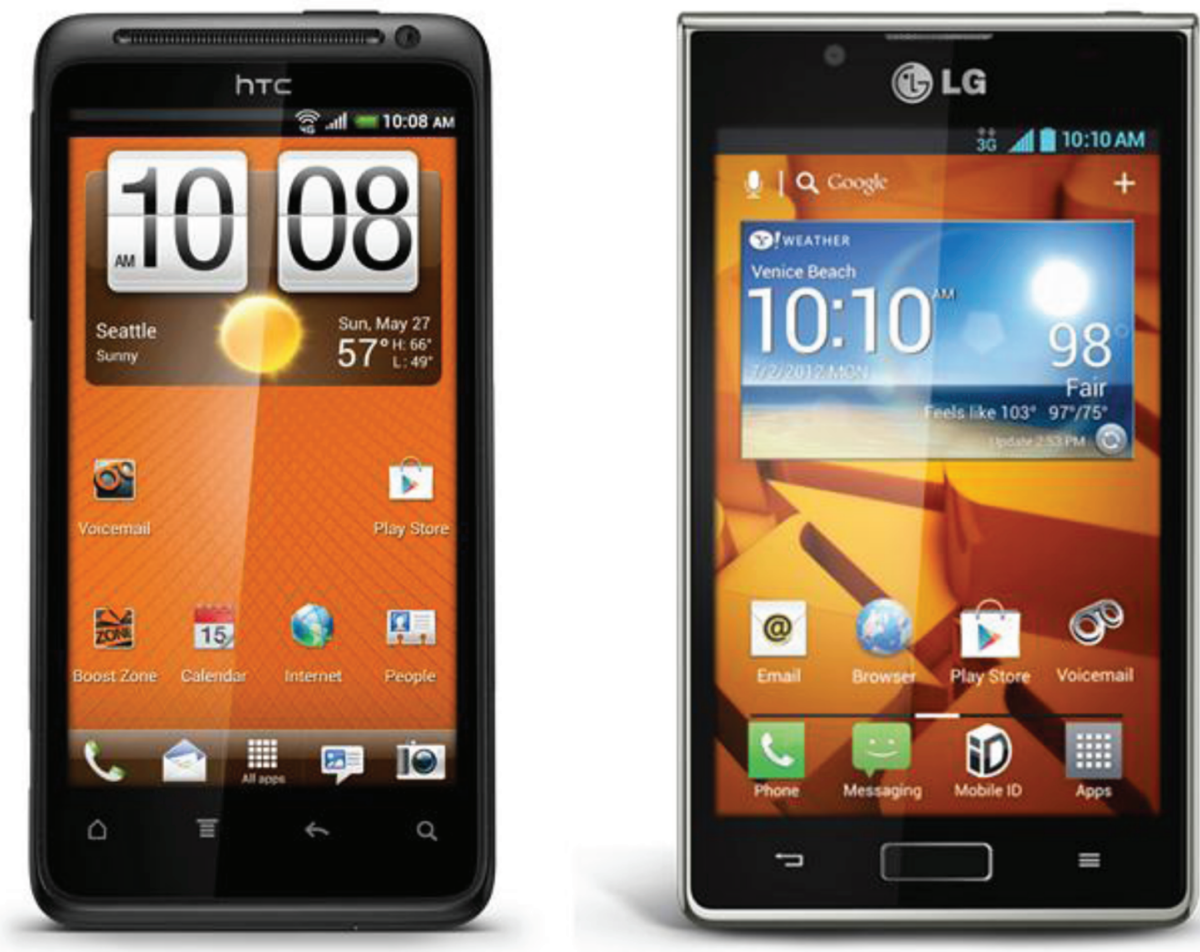

Note.-HTC EVO (left) and LG Marquee (right) touch screen mobile phones. 
FIGURE A5

PRODUCTS USED IN EXPERIMENT 6
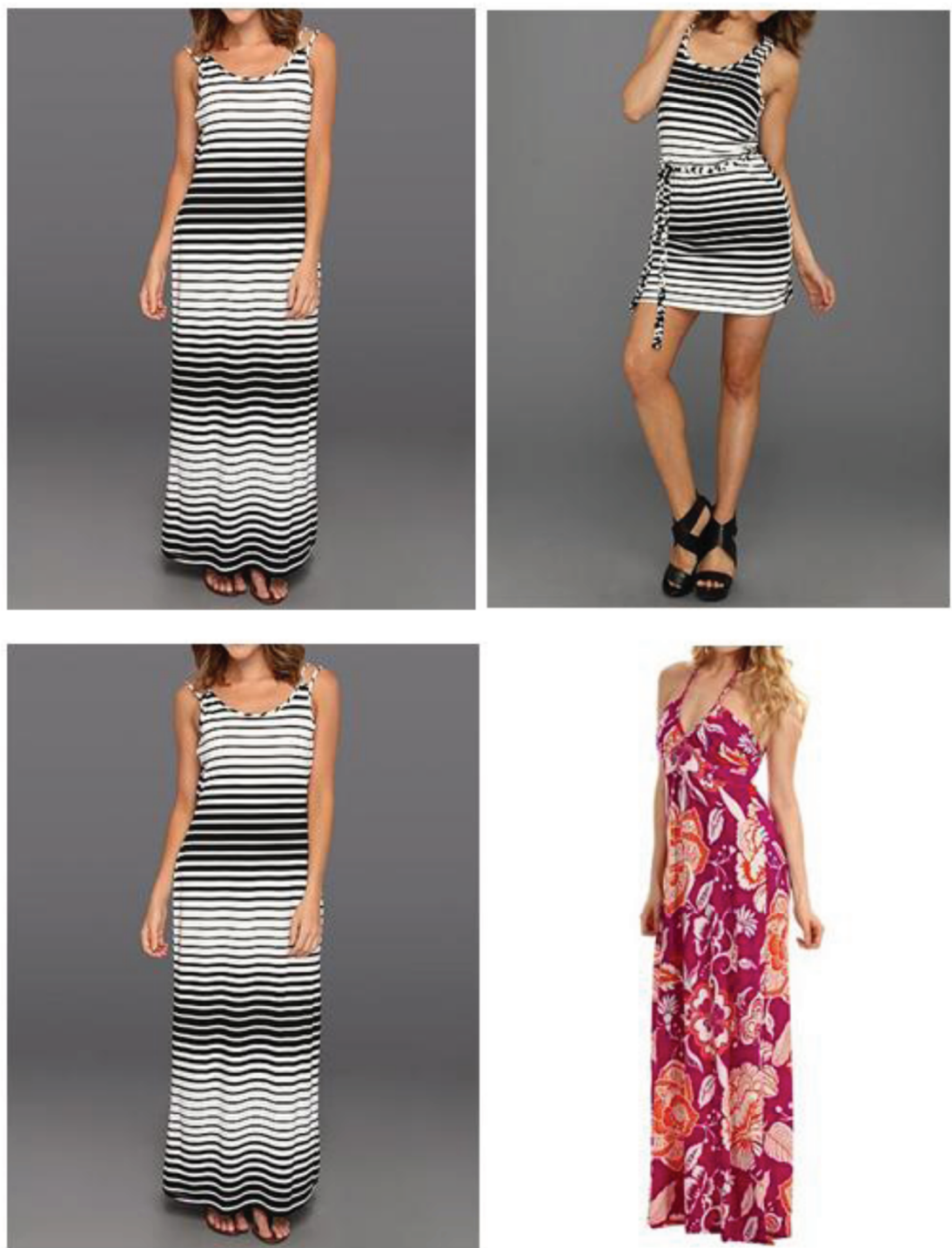

NOTE.-Component-level differences condition (top) contrasts two dresses that have similar styles of pattern (gestalt) but different cuts (component); gestalt-level differences condition (bottom) contrasts two dresses that have different styles of pattern (gestalt) but similar cuts (component).

\section{REFERENCES}

Aaker, Jennifer (1997), "Dimensions of Brand Personality,” Journal of Marketing Research, 34 (August), 347-56.

Ambady, Nalini, Frank J. Bernieri, and Jennifer A. Richeson (2000), "Toward a Histology of Social Behavior: Judgmental Accuracy from Thin Slices of the Behavioral Stream," in Advances in Experimental Social Psychology, Vol. 32, ed. Mark P. Zanna, San Diego, CA: Academic Press, 201-71.

Bartlett, Frederic C. (1932), Remembering: A Study in Experi- mental and Social Psychology, Cambridge: Cambridge University Press.

Biederman, Irving (1989), "Recognition-by-Components: A Theory of Human Image Understanding," Psychological Review, 96 (January), 115-47.

Bloch, Peter H. (1995), "Seeking the Ideal Form: Product Design and Consumer Response," Journal of Marketing, 59 (July), 16-29.

Bloch, Peter H., Frederic F. Brunel, and Todd J. Arnold (2003), "Individual Differences in the Centrality of Visual Product 
Aesthetics: Concept and Measurement," Journal of Consumer Research, 29 (March), 551-65.

Carpenter, Gregory, Rashi Glazer, and Kent Nakamoto (1994), "Meaningful Brands from Meaningless Differentiation: The Dependence on Irrelevant Attributes," Journal of Marketing Research, 31 (August), 339-50.

Corfman, Kim P. (1991), "Comparability and Comparison Levels Used in Choices among Consumer Products," Journal of Marketing Research, 28 (August), 368-74.

Förster, Jens (2009), "Relations between Perceptual and Conceptual Scope: How Global versus Local Processing Fits a Focus on Similarity versus Dissimilarity," Journal of Experimental Psychology: General, 138 (February), 88-111.

Förster, Jens, and Laura Dannenberg (2010), "GLOMO SYS: A Systems Account of Global versus Local Processing," Psychological Inquiry, 21 (September), 175-97.

Förster, Jens, Nira Liberman, and Stephanie Kuschel (2008), "The Effect of Global versus Local Processing Styles on Assimilation versus Contrast in Social Judgment," Journal of Personality and Social Psychology, 94 (April), 579-99.

Friedman, Alinda (1979), "Framing Pictures: The Role of Knowledge in Automatized Encoding and Memory for Gist," Journal of Experimental Psychology: General, 108 (September), 316-55.

Friedman, Ronald, Ayelet Fishbach, Jens Förster, and Lioba Werth (2003), "Attentional Priming Effects on Creativity," Creativity Research Journal, 15 (June), 277-86.

Grill-Spector, Kalanit, and Nancy Kanwisher (2005), "Visual Recognition: As Soon as You Know It Is There, You Know What It Is," Psychological Science, 16 (February), 152-60.

Hagtvedt, Henrik, and Vanessa M. Patrick (2008), "Art Infusion: The Influence of Visual Art on the Perception and Evaluation of Consumer Products," Journal of Marketing Research, 45 (June), 379-89.

Hekkert, Paul, and Helmut Leder (2008), "Product Aesthetics," in Product Experience, ed. Hendrik Schifferstein and Paul Hekkert, Amsterdam: Elsevier, 259-86.

Hochstein, Shaul, and Merav Ahissar (2002), "View from the Top: Hierarchies and Reverse Hierarchies in the Visual System," Neuron, 36 (December), 791-804.

Iyengar, Sheena S., and Mark R. Lepper (2000), "When Choice Is Demotivating: Can One Desire Too Much of a Good Thing?" Journal of Personality and Social Psychology, 79 (December), 995-1006.

Johnson, Michael D. (1984), "Consumer Choice Strategies for Comparing Noncomparative Alternatives," Journal of Consumer Research, 11 (December), 741-53.

Kimchi, Ruth (1992), "Primacy of Holistic Processing and Global/ Local Paradigm: A Critical Review," Psychological Bulletin, 112 (July), 24-38.

Lockhead, G. R., Paul Gruenewald, and Michael King (1978), "Holistic vs. Attribute Repetition Effects in Classifying Stimuli," Memory and Cognition, 6 (July), 438-45.

Lurie, Nicholas H., and Charlotte H. Mason (2007), "Visual Representation: Implications for Decision Making," Journal of Marketing, 71 (January), 160-77.

Mogilner, Cassie, Baba Shiv, and Sheena S. Iyengar (2013), "Eter- nal Quest for the Best: Sequential (vs. Simultaneous) Option Presentation Undermines Choice Commitment," Journal of Consumer Research, 39 (April), 1300-1312.

Mussweiler, Thomas (2001), “'Seek and ye shall find”: Antecedents of Assimilation and Contrast in Social Comparison," European Journal of Social Psychology, 31 (September), 499-509.

Navon, David (1977), "The Forest before Trees: The Precedence of Global Features in Visual Perception," Cognitive Psychology, 9 (July), 353-83.

Nedungadi, Prakash (1990), "Recall and Consumer Consideration Sets: Influencing Choice without Altering Brand Evaluations," Journal of Consumer Research, 17 (December), 263-76.

Oliva, Aude, and Antonio Torralba (2006), "Building the Gist of a Scene: The Role of Global Image Features in Recognition," Progress in Brain Research, 155 (Part B), 23-36.

Patrick, Vanessa M., and Henrik Hagtvedt (2011), "Aesthetic Incongruity Resolution," Journal of Marketing Research, 48 (April), 393-402.

Rensink, Ronald A. (2002), "Change Detection," Annual Review of Psychology, 53 (1), 245-77.

Scheibehenne, Benjamin, Rainer Greifeneder, and Peter M. Todd (2010), "Can There Ever Be Too Many Options? A Metaanalytic Review of Choice Overload," Journal of Consumer Research, 37 (October), 409-25.

Schrift, Rom Y., Oded Netzer, and Ran Kivetz (2011), "Complicating Choice," Journal of Consumer Research, 48 (April), $308-26$.

Sela, Aner, and Jonah Berger (2012), "Decision Quicksand: How Trivial Choices Suck Us In," Journal of Consumer Research, 39 (August), 360-70.

Smith, A. Mark (2001), Alhacen's Theory of Visual Perception, Philadelphia: American Philosophical Society.

Thompson, Debora V., and Rebecca W. Hamilton (2006), "The Effects of Information Processing Mode on Consumers' Response to Comparative Advertising," Journal of Consumer Research, 32 (March), 530-40.

Thompson, Debora V., Rebecca W. Hamilton, and Roland Rust (2005), "Feature Fatigue: When Product Capabilities Become Too Much of a Good Thing," Journal of Marketing Research, 42 (November), 431-42.

Townsend, Claudia, and Sanjay Sood (2011), "The Impact of Product Design on Choice: A Dual Process Explanation," in Proceedings of the Society for Consumer Psychology, ed. Adam Duhachek and Meg Meloy, St. Pete Beach, FL: Society for Consumer Psychology.

Treisman, Anne (1998), "Feature Binding, Attention and Object Perception," Philosophical Transactions of the Royal Society of London B, 353 (August), 1295-1306.

Veryzer, Robert W. (1999), "A Nonconscious Processing Explanation of Consumer Response to Product Design," Psychology and Marketing, 16 (September), 497-522.

Wilson, Timothy D. (2002), Strangers to Ourselves: Discovering the Adaptive Unconscious, Cambridge, MA: Belknap.

Zajonc, R. B. (1968), "The Attitudinal Effects of Mere Exposure," Journal of Personality and Social Psychology Monograph Supplement, 9 (June), 1-27. 